\title{
Estimating social adjustment following spinal trauma-II: Population trends and effects of compensation on adjustment
}

\author{
Clive A Glass ${ }^{1}$, Howard F Jackson ${ }^{2}$, Jonathan Dutton ${ }^{1}$, Susan Charlifue ${ }^{3}$ and Christine Orritt ${ }^{1}$ \\ ${ }^{1}$ North West Regional Spinal Injuries Centre, District General Hospital, Town Lane, Southport, Merseyside, UK; \\ ${ }^{2}$ Transitional Rehabilitation Centre, Halewood, Merseyside, UK, ${ }^{3}$ Craig Hospital Spinal Rehabilitation Centre, 3425 \\ South Clarkson Street, Englewood, Colorado, USA
}

\begin{abstract}
Adaptation to, or acceptance of, acquired spinal cord injury is accepted as an essentially longitudinal process. Changes in an individual's social, financial and domestic positions in turn affect issues concerning quality of life and self-image. The responses of 302 individuals with spinal cord injury in the United Kingdom and United States of America are presented to produce individual profiles of social adjustment. The differences between the UK and USA groups are presented, together with a combined analysis which addresses, in particular, the effects which being involved in litigation has on the process of social adjustment. Individual data concerning social adjustment, provided through a scale developed by the authors, and the utility of graphical presentation of the data is also presented. Such presentation has been found to have particular importance in clinical interview, situations by providing a framework for further exploration of individual adjustment difficulties, and in legal settings.
\end{abstract}

Keywords: spinal cord injury; adjustment; litigation; compensation

\section{Introduction}

Adjustment to spinal cord injury is an immensely complex procedure, and considerable research effort has been made to assess those factors which may be associated with 'good' or 'bad' adjustment. In the first paper, published in this journal, ${ }^{1}$ authors highlighted the individual nature of the response and adjustment to specific traumas and the absence of clear links between severity of disability and degree of psychological impairment.

In an earlier study, ${ }^{2}$ the present authors investigated the factor structure of the Modified Katz Social Adjustment Scale (MKSAS) with information provided by relatives of those with head and spinal injuries. Using the scale, which asked relatives to rate premorbid and current levels of the injured persons adjustment, it was possible to define the behavioural variables commonly associated with activity after trauma more reliably than using the original Katz social adjustment scale. ${ }^{3}$

For the spinal population it was possible to ask those who had experienced the trauma, as well as their relatives, to provide estimates of their adjustment. In providing two independent estimates of adjustment, it was considered that issues related to historical reference may be more accurately addressed, particularly for those who were longer from the time since injury.

Correspondence: CA Glass
Those with spinal cord injury completed a set of questionnaires including an estimation of social adjustment (MKSAS), a range of demographic questions and a measure of affective state. ${ }^{4}$ Examination of the reliability of questionnaire data was verified by completion of a parallel scale by a close relative of the injured person. The purpose of this article is to examine in detail the response structure of the British (UK) and American (USA) spinal injuries respondents to the demographic, affective state and MKSAS scales.

\section{Method}

Questionnaires were forwarded to 200 individuals selected randomly from the databases held within each of two participating Centres (Total $n=400$ ). The two participating centres were the Regional Spinal Injuries Centre (RSIC), Southport, England and Craig Hospital, Englewood, Colorado, USA. Information was obtained from 302 individuals following spinal trauma (75\%); 157 from the UK and 145 from the USA. The larger sample size than in the associated paper ${ }^{1}$ reflects the number of people with spinal cord injury providing complete data sets; the earlier study was reliant upon both partners completing the scales. Each person with SCI completed a lengthy questionnaire, assessing demography, injury history, affective state and social adjustment (measured by the MKSAS).

Standard statistics were undertaken on the demographic data set, and analysis of the affective state 
scale in accordance with the scoring instructions provided by the authors. ${ }^{4}$ Difference scores were calculated between pre and post-trauma estimates of adjustment using the MKSAS for each individual. The analysis of patient and relative correlation is presented in a related article ${ }^{1}$ and indicates that the responses of patient and relative are comparable. This agreement in estimates of adjustment was not affected by time since injury (TSI); there were no significant differences between the relatives and patients when the patient group was divided into the three TSI groups $(<5$ years, $5-10$ years, $>10$ years post injury).

Following the method of Jackson et $a l^{2}$ a factor structure for the spinal injured population was derived from the patients' responses to the MKSAS via a two-stage principal components analysis. Difference scores between pre-morbid and postmorbid ratings were calculated for each item, with division of the items into three broad domains; Psychosocial/Emotional adjustment, Physical/Intellectual adjustment and Psychiatric adjustment. As in the earlier paper $^{2}$ the criterion for significance of factor loading was accepted as 0.3 , with 10 experienced clinical psychologists opinions gained to name each factor. Various subgroups of the sample, as defined by demographic variables, were compared on the basis of the 37 factor scores thus derived; the factors associated with each domain, and the questions which load upon each factor, are shown in Appendix 1.

\section{Results}

\section{Demographic data}

Completed replies were received from 287 cases $(72 \%)$. Analysis of the demographic variables is included in Table 1, and highlights a number of consistent themes reported in other studies; the majority of the sample are male $(80 \%)$ and aged less than 24 at time of injury $(46 \%)$. The data also reinforces the increasing numbers of people with tetraplegia; over $50 \%$ of the present sample. Concurrent head injury was also shown in a significant number of cases $(39 \%)$.

The data were further analyzed for the two population groups which highlighted a number of significant differences between both the composition and perceptions of the UK and USA groups (Table 2). The assessment of satisfaction with physical recovery, and expectations of further physical recovery are both significantly higher for the US population. In rating their recovery to date a larger proportion of the US sample $(50 \%)$ felt their recovery to be excellent/good than the UK group $(36 \% ; P<0.008)$. In estimating expected further recovery, it is not just the case that the USA sample expect more than the UK group (USA $=19 \%, \mathrm{UK}=4 \% ; P<0.0001$ ), but also that the latter group also expect significantly less further recovery $(\mathrm{USA}=66 \%, \mathrm{UK}=84 \% ; P<0.0001)$. These factors may in part be due to the increased age and
Table 1 Demographic Variables

\begin{tabular}{|c|c|}
\hline & Frequency \\
\hline \multicolumn{2}{|l|}{ Country of origin } \\
\hline UK & 158 \\
\hline USA & 129 \\
\hline \multicolumn{2}{|l|}{ Gender } \\
\hline male & 227 \\
\hline female & 55 \\
\hline \multicolumn{2}{|l|}{ Maritual status } \\
\hline married & 145 \\
\hline single & 100 \\
\hline divorced & 32 \\
\hline widowed & 9 \\
\hline \multicolumn{2}{|l|}{ Domicle } \\
\hline home with family & 204 \\
\hline home independent & 57 \\
\hline other & 25 \\
\hline \multicolumn{2}{|l|}{ Employment status } \\
\hline occupied & 119 \\
\hline unemployed & 102 \\
\hline retired & 39 \\
\hline other & 26 \\
\hline \multicolumn{2}{|l|}{ Compensation status } \\
\hline none & 129 \\
\hline claim pending & 28 \\
\hline yes, insufficient & 78 \\
\hline yes, sufficient & 49 \\
\hline \multicolumn{2}{|l|}{ Level of injury } \\
\hline paraplegic & 137 \\
\hline tetraplegic & 146 \\
\hline \multicolumn{2}{|l|}{ Age } \\
\hline under 50 & 222 \\
\hline 50 or over & 65 \\
\hline \multicolumn{2}{|l|}{ Time since injury } \\
\hline less than 5 years & 89 \\
\hline 5 to 10 years & 113 \\
\hline over 10 years & 83 \\
\hline \multicolumn{2}{|l|}{ Age at injury } \\
\hline up to 17 & 39 \\
\hline 18 to 24 & 90 \\
\hline 25 to 39 & 94 \\
\hline 40 or over & 60 \\
\hline \multicolumn{2}{|l|}{ Severity of head injury } \\
\hline none & 126 \\
\hline less severe & 46 \\
\hline severe & 36 \\
\hline
\end{tabular}

time since injury of the UK patients (difference in mean age; $\mathrm{UK}=42$, $\mathrm{USA}=35: P<0.0001$; difference in time since injury; $\mathrm{UK}=12$ years, $\mathrm{USA}=6$ years: $P<0.0001)$.

Interestingly, the level of reported psychological difficulty is also significantly higher in the USA patient group (Percentage reporting problems; $\mathrm{UK}=8 \%$, $\mathrm{USA}=22 \%: \quad P<0.0001)$, which may similarly relate to differences attributable to age and time since injury, but which may also reflect a greater cultural and social acceptability of such expression in the USA group. There were no other differences of note between the UK and USA sample. 
Affective state

The range of depression and anxiety scores for the total patient group is outlined in Figures 1 and 2 respectively. Cut-off thresholds are defined by the authors. ${ }^{4}$

A score of 4-6 is considered borderline for depression with scores above this indicating a significant level of depression. Similarly, borderline for the anxiety scale is between six and eight with scores above this value indicating significant levels of anxiety. In the present sample no patient scored less than four for depression with over two thirds of the respondents reporting a significant degree of depression. Less than $15 \%$ of respondents reported considerable levels of anxiety.

In general, those over 50 contribute significantly more to the depressed and anxious groups, although depression scores do decrease significantly as time since injury increases. Furthermore patients with cervical injury levels show significantly higher depression scores than those with injuries between $\mathrm{t} 1-\mathrm{s}$. Anxiety scores show no similar relationship with either time since injury or lesion level.
Modified Katz social adjustment scale (MKSAS)

Previous analyses of the spinal cord injury data, ${ }^{2}$ had indicated that those persons who were married; employed; younger (under 50); and paraplegic (as opposed to tetraplegic) showed a greater degree of adjustment to their injury. Where significant differences between groups occurred, they were in agreement with these findings, although no differences were significant between the subgroups defined by marital status.

Of specific interest in this study was the effect of compensation status on the adjustment of patients, particularly those awaiting the outcome of compensation claims. All patients were asked to rate their compensation status in the demographic questionnaire; 'Did you receive financial compensation for your injuries?': Patients circled either No, Compensation pending, Yes but insufficient, or Yes sufficient. Despite the low number in this category $(n=28)$, those persons for whom compensation claims were pending showed a significantly greater increase in Depression than those who had received sufficient or no compensation. Social Dependence similarly showed

Table 2 Demography of USA and UK patients

\begin{tabular}{|c|c|c|c|c|}
\hline Variable & & $U K$ & $U S A$ & $P$ value \\
\hline Age (years) & mean & 42 & 35 & $<0.0001$ \\
\hline Gender & $\operatorname{male}(\%)$ & $86 \%$ & $73 \%$ & 0.002 \\
\hline Abode & home with family (\%) & 81 & $60 \%$ & 0.0001 \\
\hline Time since injury (years) & mean & 12 & 6 & $<0.0001$ \\
\hline Incontinent of urine & yes $(\%)$ & $81 \%$ & $63 \%$ & 0.0003 \\
\hline \multirow[t]{2}{*}{ Compensation status } & none $(\%)$ & $55 \%$ & $34 \%$ & $<0.0001$ \\
\hline & yes, sufficient $(\%)$ & $10 \%$ & $26 \%$ & $<0.0001$ \\
\hline \multirow[t]{2}{*}{ Physical recovery } & excellent/good $(\%)$ & $36 \%$ & $50 \%$ & 0.008 \\
\hline & little/none $(\%)$ & $44 \%$ & $24 \%$ & $<0.0001$ \\
\hline \multirow[t]{2}{*}{ More physical recovery } & a lot $(\%)$ & $4 \%$ & $19 \%$ & $<0.0001$ \\
\hline & little/none $(\%)$ & $84 \%$ & $66 \%$ & $<0.0001$ \\
\hline More intellectual recovery & none $(\%)$ & $39 \%$ & $13 \%$ & $<0.0001$ \\
\hline Psychological problems now & yes $(\%)$ & $8 \%$ & $22 \%$ & $<0.0001$ \\
\hline Level of injury & cervical $(\%)$ & $46 \%$ & $58 \%$ & 0.046 \\
\hline
\end{tabular}



Figure 1 Range of individual depression scores for the study population $(n=287)$. (Borderline score $4-6)$. Higher scores indicative of higher level of depression

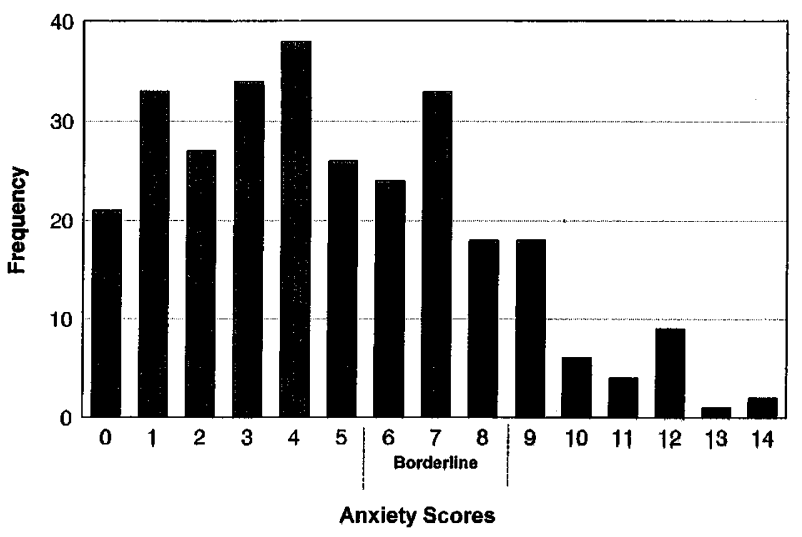

Figure 2 Range of individual anxiety scores for the study population $(n=287)$. (Borderline score $6-8)$. Higher scores indicative of higher levels of anxiety 
Table 3 Marital status, age and time since injury with compensation status

\begin{tabular}{|c|c|c|c|c|c|}
\hline & $\begin{array}{c}\text { no } \\
\text { compensation }\end{array}$ & $\begin{array}{l}\text { compensation } \\
\text { claim pending }\end{array}$ & $\begin{array}{l}\text { Compensation Status } \\
\text { compensation paid, } \\
\text { but insufficient }\end{array}$ & $\begin{array}{l}\text { sufficient } \\
\text { compensation paid }\end{array}$ & significance \\
\hline \multicolumn{6}{|l|}{ Marital staus } \\
\hline married & $55(47 \%)$ & $11(46 \%)$ & $31(43 \%)$ & $29(58 \%)$ & \multirow{4}{*}{$\begin{array}{c}\text { Likelihood Ratio } \\
P=0.02413\end{array}$} \\
\hline single & $46(39 \%)$ & $13(54 \%)$ & $24(33 \%)$ & $15(30 \%)$ & \\
\hline divorced & $13(11 \%)$ & $0(0 \%)$ & $11(15 \%)$ & $6(12 \%)$ & \\
\hline widowed & $4(3 \%)$ & $0(0 \%)$ & $6(8 \%)$ & $0(0 \%)$ & \\
\hline \multicolumn{6}{|l|}{ Age } \\
\hline under 50 & $90(76 \%)$ & $22(92 \%)$ & $59(82 \%)$ & $42(84 \%)$ & \multirow{3}{*}{$\begin{array}{c}\text { Kruskal-Wallis } \\
P=0.0073\end{array}$} \\
\hline at least 50 & $28(24 \%)$ & $2(8 \%)$ & $13(18 \%)$ & $8(16 \%)$ & \\
\hline median age & 37 & 29 & 37.5 & 37 & \\
\hline \multicolumn{6}{|l|}{ Time since injury } \\
\hline 0 to 5 years & $33(28 \%)$ & $16(67 \%)$ & $17(19 \%)$ & $13(26 \%)$ & \multirow{4}{*}{$\begin{array}{l}\text { Kruskal-Wallis } \\
\quad P<0.0001\end{array}$} \\
\hline 5 to 10 years & $46(39 \%)$ & $8(33 \%)$ & $28(31 \%)$ & $27(54 \%)$ & \\
\hline over 10 years & $39(33 \%)$ & $0(0 \%)$ & $27(30 \%)$ & $10(20 \%)$ & \\
\hline median time since injury & 7.9 & 3.9 & 9.1 & 6.3 & \\
\hline
\end{tabular}

\section{MKSAS (Post-spinal injury) Emotional Adjustment}

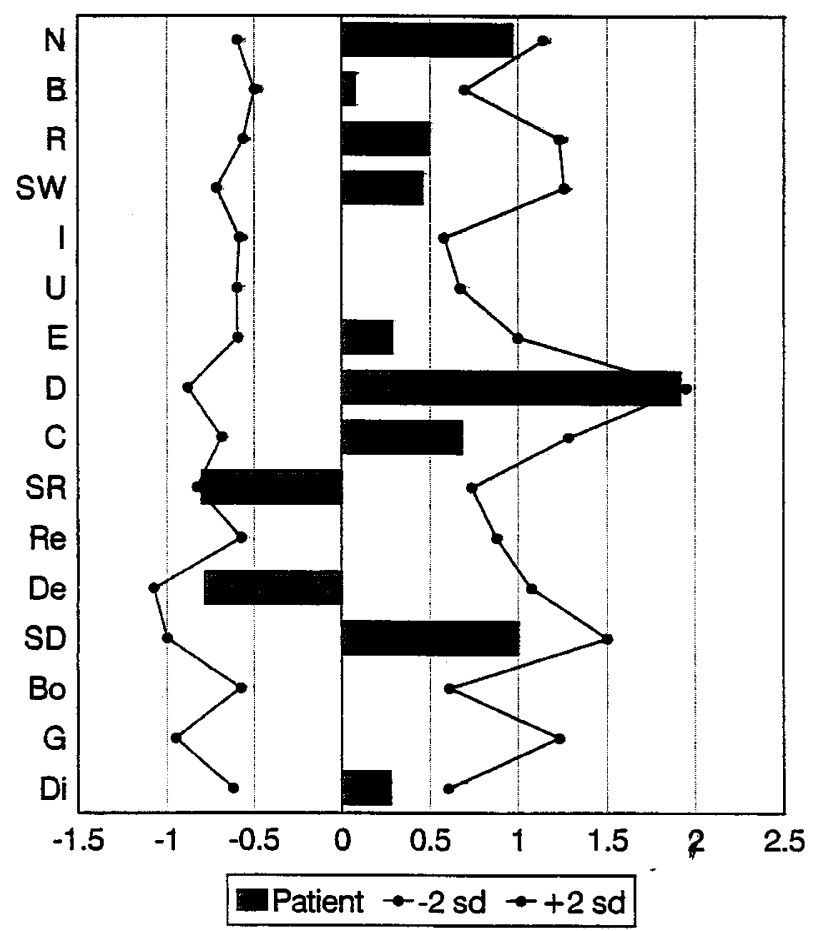

Figure 3 Individual patient's emotional adjustment score (horizontal bars) in comparison with normative range $( \pm 2$ SD) on the mkSAS. Definitions of each factor label included in Appendix 2

a significantly greater increase compared to all other groups. This trend was also evident, although nonsignificant, for Resentfulness. An interesting trend, close to significance, was for the group who had received sufficient compensation to show an increase in Apathy compared to no change for all other groups.

Those for whom compensation claims were pending tended to be single, younger, and with a shorter time since injury (Table 3 ). None of these factors alone can account for the significant results described above, since youth was found to be conducive to good adjustment, and marital status and time since injury were found to have no impact on adjustment.

\section{Discussion}

The similarity of perception between both relatives and patients concerning adjustment in the associated paper ${ }^{1}$ corroborates the reliability of this essentially historical analysis. Taking the results of the earlier factor analysis and discriminant function analysis into account it is possible to conclude that the inclusion of pre-morbid assessment using the MKSAS allows for more accurate analysis of assessment of social adjustment than had previously been possible.

The major factors associated with 'successful' adjustment appear to be younger age at injury and resolution of the compensation process. Although the prevalence of depression was greater in the older age group, depression scores decrease as time since injury increase. Causal relationships remain unclear; depression in older age groups at time of injury may relate to wider social issues of lower levels of social and family support and increasing worries over future placement. Given that depression scores decrease as time since injury increases may be perceived as supportive of overall positive adjustment in the light of increased information and experience, although the different expectations of progress to date and expected further improvement between the USA and UK populations adds to what can only be considered an essentially complex picture of adjustment. 
From clinical experience it is clear that adjustment, or rather, tolerating disability, is an idiosyncratic process, which involves individual, family, cultural, temporal and social variables. As such it might be considered that attempts to examine adjustment as a single concept appear likely to fail. However, this is not the case. Social adjustment to spinal cord injury remains an individualistic response dependant upon numerous psychosocial, physical, financial and situational variables. The same problems of definition also affect the wider issue of estimation of quality of life; such terms should therefore be seen as generic rather than providing estimates which might be considered to possess individual specificity. At the level of clinical intervention, specification of variables of importance to the individual remain essential and the most effective method of examining such definition is through the use of functional analystical techniques. Utilisation of functional analysis to understanding the interaction processes pertinent to each individual's adjustment rely on the specification of such potential variables. $^{5}$

The current data therefore highlight general themes which need to be addressed, if not in terms of specifying how every individual will adjust, at least in terms of which areas have some relevance to longer term adjustment and in relation to preparation of relatives and each patient for potential post-discharge problems. Indeed the differences between the UK and USA samples, which may be attributable at least in part to the greater time since injury of the former group, would appear to suggest some potential for reduction in future quality of life if the results for the USA group studies are applied directly to the UK group. Such potential has face validity if the view of tolerance rather than acceptance of disability prevails; as age and time since injury increase, levels of social support (through 'natural' losses) and consequent life satisfaction decrease, so levels of tolerance in the absence of such balancing factors similarly decrease. Such issues certainly occur in other areas of illness and disease. It is well noted, for example, that patients on renal dialysis often experience what might be considered a 'honeymoon' period for the first few weeks following the initiation of dialysis therapy, followed by rejection of the technology once the longer term implications of the therapy become more apparent. ${ }^{6}$ Although the differences in the UK and USA samples in the present study may be in part attributable to the sample populations, differing cultural and social perceptions of disease and illness are known to occur. Whilst longitudinal assessment of adjustment to spinal cord injury is further advanced in the USA (eg Crewe and Krause, 1992) such research with UK populations remains sparse and poorly co-ordinated; the aim of the development of the MKSAS has been to produce a scale which the individual may complete at various stages following their injury in order to examine changes specific to their adjustment.
The MKSAS completed by an individual patient therefore provides not only a framework for clinical discussion, for monitoring adjustment over time and for counselling purposes, but also (through comparison of the individuals scores with scores obtained by the other patients in the group $( \pm 2$ standard deviations)) can be used to provide a visual analogue of the specific difficulties experienced; Figure 3 highlights, as an example, one individual's difference scores 12 months post spinal cord injury, on the Emotional/Psychosocial domain of the MKSAS. Definitions of each factor abbreviation used in Figure 3 are included in Appendix 2. It will be noted in Figure 3 that the individual concerned shows difference scores, between pre- and post-injury, which approach +2 SD for increased nervousness, depressive symptomatology and social dependence, with reduced $(-2 \mathrm{SD})$ social responsiveness and determination. It should be noted that in using a more stringent $2 \mathrm{SD}$ cut-off, the difficulties of adjustment presented by the individual may be considered particularly significant. A full version of the MKSAS, together with an analysis package for use within Lotus and Excel spreadsheets (with links to Harvard Graphics), is available from the author.

Indeed, the use of the scale in clinical and medicolegal settings has shown particular promise in both highlighting areas of adjustment which the individual may have experienced difficulty in verbalising in clinical interview, and acting as a useful graphical analogue for suggesting those areas in which particular rehabilitation attention might be placed. In legal settings, in particular, highlighting areas where an individual has significantly greater adjustment difficulty than almost 300 other cases of spinal cord injury can present a powerful argument for support of further therapeutic intervention or enhancement of claim. It might be considered that an individual might be able to 'fake bad' using the scale, but given the variability and number of questions which load on each factor such false reporting is unlikely. Although further investigation is required when clinicians, involved in the definition of the factor labels, were asked to try this they either rated all scales using the extreme alternatives (resulting in all scale results well in excess of $2 \mathrm{SD}$ from the mean) or provided patterns of results which were grossly inconsistent. Indeed, in examining the medicolegal process in more detail, the adjustment profiles of those for whom compensation was pending would appear to be at odds with the general populations with whom they were compared. However, these results are considered realistic as clinical interpretation of the patterns of responding were essentially consistent with affective state difficulties. Further work using the scale is required to address whether completion is open to false reporting.

However, it is considered that the current adversarial nature of compensation claims does little to assist the individual to adapt to the modification in their life 
circumstances. Compensating loss rather than subsequent attempts at improving independence serves only to reinforce disability rather than reinforce individuals attempts to overcome their physical limitations. However there exists considerable opportunities within the present rehabilitation framework, to improve this situation. There is a need to improve communication between service providers and spinal injured patients from the point of trauma. Extending the role of the multidisciplinary team to include legal representatives could enable greater pressure to be exerted on those responsible for adaptation and community support, and this system is currently under trial at the RSIC in Southport, England. In order to ensure such an introduction is used to maximal effect it is essential that each team member has a clear role definition, and for this reason the application of case management initiatives is imperative. Such a postion may not, and indeed in many cases should not, be the medical clinician in charge of acute care; there remains an imbalance in perceived power between consultant staff and their patients and there is a danger that such patients may feel uncomfortable with the potential conflict which may arise during rehabilitation negotiation.

There remains a need to examine fully the nature of the processes which operate in personal injury litigation. The Law Commission of the United Kingdom is currently consulting on developing systems for structured settlements and interim and provisional damages ${ }^{7}$ in the light of concerns over the principles and the effectiveness of the present remedy of damages for monetary and non-monetary loss in personal injury litigation. The adversarial process does little to increase independence, serving instead to reinforce dependence and disability. Further examination must therefore be made of the feasibility of establishing goal-related financial recompense if the poor adjustment highlighted amongst those involved in compensation processes in the present investigation is to be avoided in the future.

\section{References}

1 Glass CA et al. Estimating social adjustment following spinal cord injury (1); Who is more realistic-patient or spouse? A statistical justification. Spinal Cord 1997; 35: $320-325$.

2 Jackson HF et al. The Katz Adjustment Scale: modification for use with victims of brain and spinal injury. Brain Inj 1992; 6: $109-127$.

3 Katz MM, Lyerley SB. Methods for measuring adjustment and social behaviour in the community: rationale, description, discriminative validity and scale development. Psychol Rep 1963; 13: $503-535$.

4 Snaith RP, Constantopoulos AA, Jardine MY, McGuffin P. A clinical scale for the self assessment of irritability. Brit J Psychiat 1978; 132: $164-175$.

5 Glass CA. Applying functional analysis to psychological rehabilitation following spinal cord injury. $J$ Am Para Soc 1992; 15: $187-193$.

6 Levy NB. Psychological sequelae to haemodialysis. Psychosom Med 1978; 19: 329 - 344 .

7 The Law Commission. Structured settlements and interim and provisional damages: A consultation paper. Consultation paper No. 125, HMSO, London. 


\section{Appendix 1}

Definitions of factor loadings by domain Emotional adjustment

Factor 1: Nervousness

Gets nervous easily $\quad 0.79$

Jittery $\quad 0.76$

Gets sudden fright for no reason 0.75

Worries or frets $\quad 0.67$

Has bad dreams $\quad 0.54$

Feelings get hurt easily 0.52

Afraid something terrible is going 0.48 to happen

Looks worn out

0.42

Has strange fears

0.41

Has mood changes for no reason 0.41

Is restless 0.41

Acts as if has no interest in things 0.39

Acts as though has no control 0.38 over emotions

Shy

Gets very sad, blue

0.36

0.33

0.32

0.30

Feels that people don't care

Factor 3: Belligerence

Argues $\quad 0.61$

Gets annoyed easily $\quad 0.57$

Critical of other people $\quad 0.44$

Is not co-operative $\quad 0.43$

Stubborn $\quad 0.43$

Shouts or yells for no reason $\quad 0.41$

Threatens to tell people off $\quad 0.41$

Doesn't argue (talk) back 0.38

Deliberately upsets routine $\quad 0.38$

Curses other people 0.36

Does the opposite of what is asked 0.34

Has temper tantrums $\quad 0.32$

Gives advice without being asked 0.30

Factor 4: Resentfulness

Says how bad or useless s/he is $\quad 0.65$

Envious of other people $\quad 0.64$

Resentful $\quad 0.54$

Talks about suicide $\quad 0.45$

Gets very sad, blue $\quad 0.35$

Talks about strange things going $\quad 0.34$ on inside body

Gets very self-critical

Factor 6: Social withdrawal

Prefers to be alone $\quad 0.72$

Quiet $\quad 0.54$

Gets very sad, blue $\quad 0.49$

Shy $\quad 0.43$

Stays away from people $\quad 0.40$

Feels lonely $\quad 0.35$

Feels that people don't care $\quad 0.34$
Factor 7: Irresponsibility

Is responsible $\quad-0.73$

Says or acts as if people were after $\quad 0.62$ him/her

Behaviour is childish $\quad 0.48$

Deliberately upsets routine $\quad 0.45$

Lies $\quad 0.44$

Is dependable $\quad-0.40$

Threatens to injure certain people $\quad 0.35$

Is not co-operative 0.34

Feels that people don't care $\quad 0.32$

Obedient $\quad-0.31$

Factor 8: Unsociability

Friendly $\quad-0.71$

$\begin{array}{ll}\text { Pleasant } & -0.70\end{array}$

Gets along well with people $\quad-0.69$

Gets very excited for no reason $\quad 0.33$

Curses other people $\quad 0.32$

Factor 13: Egocentricity

Thinks only of themself $\quad 0.78$

Acts as if doesn't care about other $\quad 0.62$ people's feelings

Has periods where stops moving or 0.35 doing something

Is restless $\quad 0.31$

Factor 21: Depressive symptomatology

Has trouble sleeping 0.63

Gets very self-critical $\quad 0.50$

Is restless 0.34

Factor 23: Complaining

Talks aboaut how angry s/he is at 0.74 certain people

Complains of headaches, stomach $\quad 0.36$ trouble and other physical ailments

Factor 24: Social responsiveness

Answers when talked to 0.74

Very quick to react to something you 0.65 say or do

Acts as if can't concentrate on $\quad-0.32$ one thing

Factor 26: Talking to self

Talks to him/herself $\quad 0.73$

$\begin{array}{ll}\text { Bossy } & 0.47\end{array}$

Factor 27: Determination

Tries too hard $\quad 0.69$

Is independent 0.35

Threatens to tell people off $\quad 0.32$

Factor 29: Social dependence

Talks about big future plans $\quad-0.77$

Is independent $\quad-0.37$

Needs a lot of attention $\quad 0.30$ 
Factor 30: Boastfulness

Brags about how good $\mathrm{s} / \mathrm{he}$ is

Talks too much

Forgets own address or other familiar places

Factor 33: Generousness

Generous

Factor 35: Disobedience

Obedient

Talks about people or things afraid of

Loses track of the day, month or year

Physical

Factor 5: Motor retardation

Moves about in a hurried way $\quad-0.74$

Moves about very slowly $\quad 0.71$

Clumsy

0.67

0.48

0.44

Needs to do things very slowly to get them right

Has periods where stops moving or doing something

Talks too much

Factor 10: Confusion

Acts as if in a daze

Remembers important things

Refuses to speak at all for periods of time 0.58

Acts as if don't know where they are $\quad 0.56$

Very slow to react

Factor 11: Abnormal movements

Gets into peculiar positions

Makes peculiar movements

Needs to do things very slowly to get them right

Talks without making sense

Hands tremble

0.36

0.32

0.31

Factor 12: Restricted communication

Acts as if wants to speak but can't

Keeps changing subject for no reason

0.70

0.65

Talks as if has committed the

0.37

worst sins

Does the opposite of what is asked

0.32

Talks without making sense

0.32

Factor 15: General cognitive dysfunction

Remembers the names of people $s /$ he knows well

Forgets own address or other familiar places

Acts as if don't know where they are

Factor 16: Apathy

Will stay in one position for a long period

0.76

Just sits

0.48

Needs a lot of attention

0.32

Factor 17: Slow speech

Speaks very slowly $\quad 0.80$

Speaks very fast

$-0.54$

Factor 18: Volume of speech

Speaks very loudly

0.82

Speaks so low can't be heard

$-0.42$

Factor 31:Unclear speech

Speaks clearly

$-0.80$

Hard to understand their words

Factor 32: Arousal disorder

Passes out

Has bad dreams

Factor 37: Hyperactivity

Needs a lot of attention

0.44

Acts as if can't get certain thoughts

0.36

out of his/her mind

Acts as if has no interest in things $\quad-0.33$

Hands tremble

0.32

Psychiatric

Gets very happy for no reason $\quad 0.77$

Acts as though seeing people or things $\quad 0.67$ that aren't there

Laughs or cries at strange things $\quad 0.61$

Does strange things without reason 0.52

Hard to understand their words 0.52

Does the same thing over and over $\quad 0.51$ without reason

Has temper tantrums $\quad 0.44$

Acts as though has no control over $\quad 0.43$ emotions

Has mood changes for no reason $\quad 0.41$

Argues 0.38

Has strange fears $\quad 0.36$

Acts as if can't concentrate on $\quad 0.34$ one thing

Acts helpless $\quad 0.32$

Has bad dreams $\quad 0.32$

Says the same thing over and over $\quad 0.32$

Talks without making sense 0.32

Complains about people and things in general

0.30

Factor 9: Paranoid ideation

Says that people are talking about $\quad 0.77$ $\operatorname{him} /$ her

Thinks people are talking about $\quad 0.70$ $\operatorname{him} /$ her

Factor 14: Fear of losing control Afraid might injure somebody

Afraid of not being able to 
control self

Gets into trouble with the law

Shows good judgement

Factor 19: Antisocial behaviour

Gets drunk

Takes non-prescribed drugs

0.43

Talks about people or things afraid of

Gets into fights with people

Factor 20: Psychiatric anxiety

Says something terrible is going to happen

Afraid something terrible is going to happen

Factor 22: Repetitiveness

Keeps repeating the same idea

0.66

Says the same thing over and over

0.48

Cries easily

$-0.31$

Factor 25: Suicidal inclination

Attempts suicide

Gets angry and breaks things

0.73

0.46

Threatens to injure certain people

Gets into fights with people

Acts as though seeing people or things

that aren't there

Factor 28: Suspicion

Acts as if suspicious of people

Factor 34: Strange beliefs

Believes in strange things

Factor 36: Strange sexual thought

Talks about strange sexual ideas

Shouts or yells for no reason

Very slow to react

0.73

0.33

\section{Appendix 2}

Emotional adjustment

$\begin{array}{ll}\mathrm{N} & \text { Nervousness } \\ \mathrm{B} & \text { Belligerence }\end{array}$

R Resentfulness

SW

I

U

E

D

C

SR

Re

De

SD

B

G

Di

Physical adjustment MR

$\mathrm{C}$

AM

$\mathrm{RC}$

GCD

A

SS

VS

US

AD

$\mathrm{H}$

Social Withdrawal

Irresponsibility

Unsociability

Egocentricity

Depressive symptomatology

Complaining

Social responsiveness

Resistance

Determination

Social dependence

Boastfulness

Generousness

Disobedience

Motor retardation

Confusion

Abnormal movements

Restricted communication

General cognitive dysfunction

Apathy

Slow speech

Volume of speech

Unclear speech

Arousal disorder

Hyperactivity

Psychiatric adjustment

$$
\text { PD }
$$

PI

FLC

AB

PA

R

SI

$\mathrm{S}$

SB

SD
Psychiatric depression

Paranoid ideation

Fear of losing control

Antisocial behaviour

Psychiatric anxiety

Repetiveness

Suicidal inclination

Suspiciousness

Strange beliefs

Sexual dysfunction 